\title{
In vivo effects of the NLRP1/NLRP3 inflammasome pathway on latent respiratory virus infection
}

\author{
YONG-HUAI LI ${ }^{1}$, XIANG WEI ${ }^{2}$, SHUANG JI ${ }^{1}$, SHU-YU GUI ${ }^{1}$ and SU-MEI ZHANG ${ }^{2}$ \\ ${ }^{1}$ Department of Respiratory Medicine, The First Affiliated Hospital of Anhui Medical University, \\ Hefei, Anhui 230022; ${ }^{2}$ Laboratory of Molecular Biology and Department of Biochemistry, \\ Anhui Medical University, Hefei, Anhui 230032, P.R. China
}

Received April 17, 2017; Accepted February 8, 2018

DOI: $10.3892 / \mathrm{ijmm} .2018 .3521$

\begin{abstract}
The present study aimed to investigate the effects of nucleotide-binding domain leucine-rich repeat protein (NLRP)1/NLRP3 inflammasome pathways on latent viral infection of the respiratory tract. A total of $55 \mathrm{BALB} / \mathrm{c}$ mice were assigned to the control, bleomycin (BLM)-treated, murine cytomegalovirus (MCMV), MCMV+BLM and $\mathrm{MCMV}+\mathrm{BLM}+\mathrm{CD} 4{ }^{+} \mathrm{T}$-cell groups. The viral loads were detected in the salivary glands, kidney, liver and lung tissues via polymerase chain reaction (PCR). The weight, lung coefficient and hydroxyproline (HYP) were detected. HE and Masson staining were performed to score for alveolitis and degree of pulmonary fibrosis. Reverse transcription-quantitative PCR and western blot were applied to assess the expression levels of the NLRP inflammasome components caspase-1, interleukin (IL)-1 $\beta$ and IL-18. ELISA was used to evaluate the expression levels of caspase-1, tumor necrosis factor (TNF)- $\alpha$, IL-1 $\beta$ and IL-18. The weight of the mice decreased, and the lung coefficient and HYP content increased in the BLM, $\mathrm{MCMV}, \mathrm{MCMV}+\mathrm{BLM}$ and $\mathrm{MCMV}+\mathrm{BLM}+\mathrm{CD} 4^{+} \mathrm{T}-\mathrm{cell}$ groups compared with those in the control group. Compared with the control group, mice in the BLM, MCMV+BLM and $\mathrm{MCMV+BLM+CD} 4^{+} \mathrm{T}$-cell groups had obviously increased alveolitis and degrees of pulmonary fibrosis, increased mRNA expression levels of caspase-1, IL-1 $\beta$ and IL-18, and increased protein expression levels of caspase-1(p20), mature IL-1 $\beta$ and mature IL-18. The values in the MCMV+BLM group were also higher than those in the BLM group and those in the MCMV+BLM+CD4 ${ }^{+}$T-cell group. The serum levels of caspase-1, TNF- $\alpha$, IL- $1 \beta$ and IL-18 in the serum of mice in the MCMV+BLM group were significantly higher than those
\end{abstract}

Correspondence to: Dr Yong-Huai Li, Department of Respiratory Medicine, The First Affiliated Hospital of Anhui Medical University, 218 Jixi Road, Shushan, Hefei, Anhui 230022, P.R. China

E-mail: liyonghuaihefei@163.com

Key words: nucleotide-binding domain leucine-rich repeat protein 1 , nucleotide-binding domain leucine-rich repeat protein 3 , inflammasome, cytomegalovirus, pulmonary fibrosis in the BLM group. Compared with the MCMV+BLM group, the MCMV+BLM+CD4 ${ }^{+}$T-cell group had decreased levels of caspase-1, TNF- $\alpha$, IL-1 $\beta$ and IL-18 (all P<0.05). These results demonstrated that the activation of the NLRP1 and NLRP3 inflammasome pathways may contribute to pulmonary fibrosis caused by latent MCMV infection in mice.

\section{Introduction}

Idiopathic pulmonary fibrosis (IPF), also called cryptogenic fibrosing alveolitis, is a devastating, age-associated lung disease with a generally fatal outcome of undefined cause $(1,2)$. As an uncommon disease, IPF has an incidence of 13-42 cases per 100,000 individuals, and it mainly affects aged individuals ( $>50$ years) (3). This type of disease was once considered a chronic inflammatory condition, but a recent study revealed that the fibrotic response is caused by abnormally activated alveolar epithelial cells (4). The typical symptoms of IPF include disabling fatigue and exertional breathlessness, and it is continually accompanied by a non-productive cough (5). Numerous types of common pathologic features have been reported for IPF patients, including inflammation with lymphocytes, neutrophils and macrophages as well as damage to endothelial and epithelial cells, which is followed by proliferation of collagen deposition and fibroblasts (6). A previous study demonstrated that IPF has a complex pathogenesis involving cytokines, mediators and growth factors, and multiple cell types within the lung contribute to IPF (7). No therapy has been proven effective, and the median survival time for patients who succumbed to IPF is $\sim 3$ years from the time of diagnosis $(8,9)$. As a result, the diagnosis and treatment of IPF have received considerable attention.

Nucleotide-binding domain leucine-rich repeat proteins (NLRPs) are involved in immunity and disease via their ability to regulate inflammatory reactions to pathogen-derived and endogenous damage signaling (10). Activation of NLRPs may result in the formation of multiprotein inflammasome complexes, which may be considered stages for the activation of inflammatory caspases by their cleavage and recruitment (11). Previous evidence has revealed that NLRP1 regulates the innate immune response, and its expression may be detected in numerous immunocompetent cell types (12). In addition, NLRP1 is correlated with certain autoimmune 
diseases, including type 1 diabetes, generalized vitiligo, rheumatoid arthritis and Addison disease (13). The NLRP1 inflammasome consists of NLRP1, and it was the first to be discovered as an apoptosis-associated speck-like protein, which contains one caspase-activating recruitment domain and caspase-1 (14). Among the NLRP family members, the NLRP3 inflammasome has been involved in distinguishing non-microbial origin damage-associated molecular patterns (DAMPs), including extracellular ATP, urate crystals, asbestos and silica. $\beta$-amyloid NLRP3 is known to be present in several tissue and cell types (15). As demonstrated by a previous study, the NLRP3 inflammasome has a crucial role in the pathogenesis of fibrotic respiratory diseases (16). The mechanistic involvement of the NLRP1 and NLRP3 inflammasome pathways in pulmonary fibrosis has remained to be demonstrated; therefore, the present study investigated the effects of the NLRP1 and NLRP3 inflammasome pathways on murine cytomegalovirus (MCMV)-induced pulmonary fibrosis in mice.

\section{Materials and methods}

Animal experiment. A total of 77 BALB/c mice (age, 8 weeks; weight, $18.0 \pm 2.0 \mathrm{~g}$ ), purchased from the Shanghai Experimental Animal Center of the Chinese Academy of Sciences (Shanghai, China), were used in the present study. All specific-pathogen-free (SPF) mice were kept in an isolated cage (individual ventilated cages, Suzhou Science \& Education Equipment Co., Ltd, Suzhou, China) to prevent infection from which 55 mice were randomly selected and divided into the following 5 groups containing 11 mice in each group: Control, bleomycin (BLM), MCMV, MCMV+BLM (BLM was added after MCMV infection) and MCMV+BLM+CD4 ${ }^{+} \mathrm{T}$-cell group (BLM was added after MCMV infection and then $\mathrm{CD} 4^{+} \mathrm{T}$-cells were injected). All mice were fed with standard feed, free access to food and water, the feeding temperature was $18-22^{\circ} \mathrm{C}$ with relative humidity of $60 \pm 10 \%$, under a $12 \mathrm{~h}$ light/dark. The details concerning grouping and treatment are displayed in Table I. The MCMV Smith strain used in the present study was purchased from the American Type Culture Collection (Manassas, VA, USA). Virus multiplication was performed in the salivary glands of an additional $20 \mathrm{BALB} / \mathrm{c}$ mice, house under the aforementioned conditions; the strain was collected for the subsequent experiment. The experimental method was approved by the animal ethics committee of the First Affiliated Hospital of Anhui Medical University (Hefei, China). The animal experiment was performed in strict accordance with the Guidelines for the Care and Use of Laboratory Animals (17).

Isolation and culture of mouse spleen T lymphocytes. Following an intraperitoneal injection of $1 \%$ pentobarbital sodium $(30 \mathrm{mg} / \mathrm{kg})$, two mice were sacrificed by cervical dislocation and their spleens were collected under sterile conditions. These spleens were added into the phosphate buffer to create a suspension. The suspension was added on the top of a lymphocyte separation solution (1:2) for centrifugation at 1,200 x g for $20 \mathrm{~min}$ to collect the splenic lymphocytes $\left(1.5 \times 10^{8}\right.$ cells $)$. Mouse lymphocytes were then isolated with $37^{\circ} \mathrm{C}$ pre-heated PBS containing 5\% fetal calf serum (Hyclone; GE Healthcare Life Sciences, Logan, UT, USA) and diluted into $2 \mathrm{ml}$, which was followed by placement on a nylon wool column $(4 \mathrm{~cm}$ in height, Polysciences Inc., Warrington, PA, USA) for incubation at $37^{\circ} \mathrm{C}$ for $60 \mathrm{~min}$. Subsequently, the column was washed with $5 \mathrm{ml}$ nylon buffer solution pre-heated at $37^{\circ} \mathrm{C}$ with a flow rate of $0.5 \mathrm{ml} / \mathrm{min}$. The eluates were collected and considered $\mathrm{T}$ lymphocytes. Another $5 \mathrm{ml}$ of nylon buffer solution was used to wash the remaining $\mathrm{T}$ lymphocytes. In addition, another nylon wool column (4 com in height, Polysciences Inc.) was used to separate and purify the cells, which was followed by the collation of T lymphocytes. The T lymphocytes were added to $0.5 \mu \mathrm{g} / \mathrm{ml}$ soluble anti-CD3 antibody (1:25, AB_2228819, eBiosciences; Thermo Fisher Scientific Inc., Waltham, MA, USA) to collect activated CD4 ${ }^{+}$T-cells.

Model establishment and detection of viral load. The MCMV passaged in salivary glands of BALB/c mice was suspended in Hank's solution (Thermo Fisher Scientific Inc.) containing $200 \mu 13 \%$ fetal bovine serum (FBS, Hyclone; GE Healthcare Life Sciences). A total of 33 mice were randomly selected, and $10^{5}$ PFU MCMV was intraperitoneally injected for infection (18). The remaining 22 mice were intraperitoneally injected with Hank's solution containing $200 \mu 1$ 3\% FBS and were used as the controls. After treatment with MCMV for 3,14 or 28 days, infected mice $(n=3)$ and uninfected mice $(n=3)$ were randomly selected to assess the viral loads in the salivary glands, kidneys, liver and lungs via semi-quantitative reverse-transcription polymerase chain reaction (RT-PCR). The mouse specimens from salivary glands, kidney, liver and lungs were homogenized, respectively. PBS was added to the homogenate and then centrifuged at $1,500 \mathrm{x}$ g for $10 \mathrm{~min}$; the supernatant was then collected. Total RNA was extracted from the supernatant using an RNeasy Mini kit (cat. no. 74106, Qiagen, Inc., Valencia, CA, USA) according to the manufacturer's protocols and subsequently reverse-transcribed into cDNA using a RT2 First Strand kit (330404, Qiagen, Inc.) according to the manufacturer's protocols. The cDNA was subjected to amplification by RT-PCR. The reaction system $(25 \mu \mathrm{l})$ was as follows: $2.5 \mu \mathrm{l} 10 \mathrm{X}$ buffer (containing $15 \mathrm{mmol} / \mathrm{l} \mathrm{Mg}^{2+}$ ), $1.0 \mu \mathrm{l}$ deoxynucleoside triphosphate $(2.5 \mathrm{mmol} / \mathrm{l}), 0.35 \mu \mathrm{l}$ forward primer $(25 \mu \mathrm{mol} / \mathrm{l}), 0.35 \mu \mathrm{l}$ reverse primer ( $25 \mu \mathrm{mol} / \mathrm{l}), 0.3 \mu \mathrm{l}$ Taq DNA polymerase $(5 \mathrm{U} / \mu \mathrm{l}), 19.5 \mu \mathrm{l}$ double-distilled $\mathrm{H}_{2} \mathrm{O}$ and $1 \mu \mathrm{l}$ template. The forward primer was 5'-ATCTGGTGCTCC TCAGATCAGCTAA-3' and the reverse primer was 5'-ATT GTTCATTGCCTGGGGAGTTT-3'. GAPDH served as the internal reference: Forward, 5'-CCACAGTCCATGCCATCA CT-3' and reverse, 5'-TCCACCACCCTGTTGCTGTAG-3'. The PCR reaction conditions were as follows: 40 cycles of $95^{\circ} \mathrm{C}$ for $10 \mathrm{~min}, 94^{\circ} \mathrm{C}$ for $1 \mathrm{~min}, 63^{\circ} \mathrm{C}$ for $30 \mathrm{sec}$ and $72^{\circ} \mathrm{C}$ for $1 \mathrm{~min}$ with a final elongation at $70^{\circ} \mathrm{C}$ for $7 \mathrm{~min}$ and $4^{\circ} \mathrm{C}$ at $5 \mathrm{~min}$ to stop the reaction. The experiment was performed three times; the PCR product was subjected to $2 \%$ agarose gel electrophoresis with ethidium bromide staining and observed under an ultraviolet lamp, and the gray value was detected by ImageJ software (v1.44, National Institutes of Health, Bethesda, MD, USA). Following treatment with MCMV for 4 weeks, mice infected with MCMV were divided into the MCMV, MCMV+BLM and $\mathrm{MCMV}+\mathrm{BLM}+\mathrm{CD}^{+}{ }^{+} \mathrm{T}$ groups, and mice without $\mathrm{MCMV}$ infection were assigned to the control and BLM groups with 11 mice in each group. Mice in the MCMV, MCMV+BLM and $\mathrm{MCMV}+\mathrm{BLM}+\mathrm{CD} 4^{+} \mathrm{T}$ groups were treated by sevoflurane 
Table I. Treatment regimens.

Group

Treatment regimen

Control
BLM
MCMV
MCMV + BLM
MCMV + BLM + CD4 ${ }^{+} \mathrm{T}$

Hank's solution $(200 \mu 1)$ and PBS $(80 \mu 1)$

Hank's solution $(200 \mu \mathrm{l})$ and $3 \mathrm{mg} / \mathrm{kg}$ BLM [vehicle: PBS (80 $\mu \mathrm{l})$ ]

$10^{5}$ PFU MCMV [vehicle: Hank's solution (200 $\left.\mu 1\right)$ ] and PBS $(80 \mu 1)$

$10^{5} \mathrm{PFU}$ MCMV and $3 \mathrm{mg} / \mathrm{kg}$ BLM

$10^{5} \mathrm{PFU}$ MCMV, $3 \mathrm{mg} / \mathrm{kg} \mathrm{BLM}(80 \mu \mathrm{l})$ and $1 \times 10^{7} \mathrm{CD}^{+} \mathrm{T}$

BLM, bleomycin; MCMV, murine cytomegalovirus; T, T-tells.

Table II. Primer sequences for polymerase chain reaction.

\begin{tabular}{lll}
\hline mRNA & \multicolumn{1}{c}{ Forward primer (5'-3') } & \multicolumn{1}{c}{ Reverse primer (5'-3') } \\
\hline IL-1 $\beta$ & TCTTTGAAGTTGACGGACCC & TGAGTGATACTGCCTGCCTG \\
IL-18 & ACATCCGAAGCAACAAGC & CGAAGTGAGAAGGCAACA \\
Caspase-1 & TGGAAGGTAGGCAAGACT & ATAGTGGGCATCTGGGTC \\
GAPDH & ACCACAGTCCATGCCATCAC & TCCACCACCCTGTTGCTGTA \\
\hline
\end{tabular}

IL, interleukin.

inhalation anesthesia (Abbott Laboratories, Abbott Park, IL, USA), and the supine position was used for treatment with $80 \mu \mathrm{l} \mathrm{BLM}(0.75 \mathrm{U} / \mathrm{ml})$ via tracheal intubation. At the same time, mice in the $\mathrm{MCMV}+\mathrm{BLM}+\mathrm{CD} 4^{+} \mathrm{T}$ group were intravenously injected with $1 \times 10^{7} / \mathrm{ml}(1 \mathrm{ml}) \mathrm{CD}^{+} \mathrm{T}(19)$. Mice in the MCMV and control groups were injected with an isodose of PBS, and animals were sacrificed after 4 weeks.

Detection of the weight, lung coefficient and hydroxyproline $(H Y P)$. The mice were weighed prior to model establishment and at the end of the experiment. After the model was established on the 28th day, all mice were sacrificed and the trachea was intubated, which was followed by lavage of lung tissues using $0.5 \mathrm{ml}$ PBS. Subsequently, the lung tissues were weighed and the lung coefficient was calculated using the following formula: Lung coefficient=wet weight of both lungs (mg)/weight ( $\mathrm{g}$ ). The HYP content in mouse lung tissues was detected by alkaline hydrolysis and spectrophotography according to the instructions of the HYP kit (A030-2, Nanjing Jiancheng Bioengineering Institute, Nanjing, China).

Histopathological observation. Following an intraperitoneal injection of $1 \%$ pentobarbital sodium $(30 \mathrm{mg} / \mathrm{kg})$, the mice were killed by 3-5-min exsanguination via the abdominal aorta. The anocelia was opened immediately, and the right main bronchus was ligated, which was followed by injection of $4 \%$ paraformaldehyde (Wuhan Boster Biological Technology Ltd., Wuhan, China) via the trachea to fix the right lung tissues. Subsequently, the lung tissues were immediately removed, fixed in $4 \%$ paraformaldehyde at $4^{\circ} \mathrm{C}$ for $24 \mathrm{~h}$, dehydrated by gradient ethanol (75, 85, 95 and $100 \%$, for 3 min each), embedded in paraffin and sectioned into $5-\mu \mathrm{m}$ serial tissue sections. The sections were dewaxed in dimethylbenzene and hydrated in gradient ethanol
(100, 95, 85 and, $75 \%$ for $3 \mathrm{~min}$ each). At room temperature, hematoxylin and eosin (HE) staining was performed to evaluate histopathological changes of lung tissues and Masson staining was performed to evaluate collagen deposition. Alveolitis and the degree of pulmonary fibrosis were scored by $\mathrm{HE}$ and Masson staining as in the study by Szapiel et al (20): 1 point-no; 2 points-mild; 3 points-moderate; 4 points-severe.

RT-quantitative PCR analysis. Total RNA of lung tissues was extracted according to the instructions of RNeasy Mini kit. The RNA concentration was determined via optical density (OD) measurement at 260/280 nm using an ultraviolet spectrophotometer, and the sample was preserved at $-80^{\circ} \mathrm{C}$. RT was performed to synthetize complementary DNA according to the RT2 First Strand kit's instructions (cat. no. 330404, Qiagen, Inc.). Primers were designed based on the gene sequence published in the GenBank database. The sequences of the primers are presented in Table II and were synthesized by Sangon Biotech Co., Ltd. (Shanghai, China). The PCR system (20 $\mu \mathrm{l})$ had the following components: $10 \mu \mathrm{l} \mathrm{SYBR}$ PremixExTaq (2X), $0.8 \mu \mathrm{l}$ forward primer $(10 \mu \mathrm{M}), 0.8 \mu \mathrm{l}$ reverse primer $(10 \mu \mathrm{M}), 0.4 \mu \mathrm{l}$ ROX Reference Dye II (50X), $2 \mu$ l DNA template and $6.0 \mu \mathrm{l}$ double-distilled $\mathrm{H}_{2} \mathrm{O}$. The reaction conditions were as follows: Pre-denaturation at $95^{\circ} \mathrm{C}$ for $30 \mathrm{sec}$, denaturation at $95^{\circ} \mathrm{C}$ for $5 \mathrm{sec}$, annealing at $60^{\circ} \mathrm{C}$ for $30 \mathrm{sec}$ and elongation at $72^{\circ} \mathrm{C}$ for $30 \mathrm{sec}$ for a total of 40 cycles. GAPDH was used as an internal reference. The reliability of the PCR results was evaluated by a dissolution curve. The $\mathrm{Cq}$ value (the inflection point on the amplification power curve) was determined, and the relative expression of the target gene was calculated as $2^{-\Delta \Delta C q}(21)$.

Western blot analysis. The lung tissues $(20 \mathrm{mg})$ were ground in liquid nitrogen using a mortar and pestle, and dissociated 
in $250 \mu 1$ radioimmunoprecipitation assay buffer $(\mathrm{P} 0013 \mathrm{C}$, Beyotime Institute of Biotechnology, Jiangsu, China) for the extraction of total protein. The concentration of the total protein was detected based on the instructions of the bicinchoninic acid kit (Wuhan Boster Biological Technology, Ltd.). After the addition of sample buffer solution, the extracted protein was heated at $95^{\circ} \mathrm{C}$ for $10 \mathrm{~min}$, and separated and purified using 10\% SDS-PAGE (Wuhan Boster Biological Technology, Ltd.) with $30 \mu \mathrm{g}$ total protein loaded per well. The protein was transferred to a polyvinylidene fluoride membrane (Sigma-Aldrich; Merck KGaA, Darmstadt, Germany) using the semi-dry film method, followed by blocking with $5 \%$ bovine serum albumin (ST023, Beyotime Institute of Biotechnology) at room temperature for $1 \mathrm{~h}$. Subsequently, primary antibodies to mature caspase-1 (1:1,000; ab62698), pro-caspase-1 (1:1,000; ab179515), interleukin (IL)-1 $\beta$ (1:1,000, ab106035) and IL-18 $(1: 1,000, a b 207323)$ and GAPDH $(1: 2,500, a b 9485)$ (all from Abcam) were added, followed by incubation at $4^{\circ} \mathrm{C}$ overnight. The membrane was washed 3 times with Tris-buffered saline containing Tween-20 for 5 min each time, followed by addition of relevant secondary antibody, goat anti-rabbit immunoglobulin G (1:2,000, ab205718, Abcam) for incubation at room temperature for $1 \mathrm{~h}$. The membrane was washed 3 times for $5 \mathrm{~min}$ each and developed using a chemiluminescence reagent (36222ES60, Yeasen Biotechnology, Co., Ltd., Shanghai, China). GAPDH was used as an internal reference. The Bio-Rad Gel Dol EZ Imager (Bio-Rad Laboratories, Inc., Hercules, CA, USA) was used for development. Gray value analysis of protein bands was performed using ImageJ software (v1.44, National Institutes of Health).

ELISA. At the end of the experiment, a total of 3-5 $\mathrm{ml}$ blood was collected from the abdominal aorta and preserved at $4{ }^{\circ} \mathrm{C}$ in a refrigerator, which was followed by centrifugation at $2,400 \times \mathrm{g}$ for $10 \mathrm{~min}$ at $4^{\circ} \mathrm{C}$. Subsequently, the serum phase was collected and placed in numbered tubes with $200 \mu \mathrm{l}$ in each tube, which was followed by preservation at $-80^{\circ} \mathrm{C}$. The analysis of the serum levels of caspase-1 (AG-45B-0002), TNF- $\alpha$ (ADI-900-047), IL-1 $\beta$ (ADI-900-132A) and IL-18 (bsk00297) was performed in strict accordance with the ELISA kit instructions (Shanghai Meilian Biotechnology Co., Ltd., Shanghai, China).

Statistical analysis. SPSS 18.0 software (SPSS Inc, Chicago, IL, USA) was applied for statistical analysis. Values are expressed as the mean \pm standard deviation. Comparison of measurement data that followed a normal distribution between two groups was evaluated by the Student's two-tailed t-test, and comparison among multiple groups was performed by one-way analysis of variance. Post hoc multiple comparisons were achieved by means of least significance difference method if homogeneity of variance was appropriate otherwise the non-parametric Kruskal-Wallis test was employed. $\mathrm{P}<0.05$ was considered to indicate a statistically significant difference.

\section{Results}

MCMV DNA load is stable in the salivary glands of mice. The viral load in various tissue types of the MCMV-infected mice

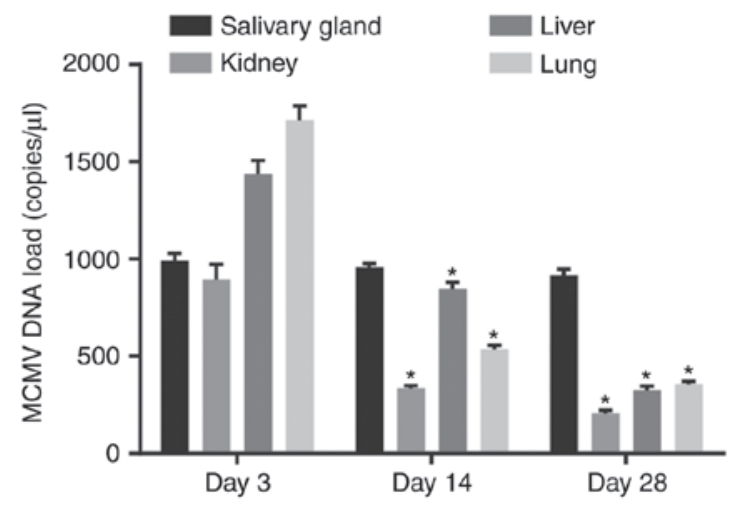

Figure 1. Detection of the viral load in mice with/without MCMV treatment. Quantitative polymerase chain reaction analysis was used to determine the viral DNA load. ${ }^{*} \mathrm{P}<0.05$ compared with the viral load after inoculation for 3 days. MCMV, murine cytomegalovirus.

at 3,14 , and 28 days following treatment is presented in Fig. 1. MCMV DNA was not detected in mice without MCMV treatment, while it was detectable in the salivary glands, kidneys, liver and lungs of mice treated with MCMV. The MCMV DNA content in the kidney, liver and lungs of mice treated with MCMV was highest at 3 days after inoculation. In addition to the salivary glands, the viral load was gradually reduced and maintained at a low level in other tissues, which was similar to the observations in humans with latent infection.

BLM exacerbates but $C D 4^{+} T$-cell injection ameliorates lung tissue damage associated with latent respiratory virus infection. The weight, lung coefficient and HYP content of mice in each group are displayed in Fig. 2. Prior to modeling, no significant difference was identified in the murine weight $(\mathrm{P}>0.05)$. Compared with the control group, the weight of mice in the BLM, MCMV, BLM+MCMV and $\mathrm{MCMV}+\mathrm{BLM}+\mathrm{CD} 4^{+} \mathrm{T}$ groups was significantly decreased at the end of the experiment, and the weight in the MCMV+BLM group was significantly lower than that in the BLM, MCMV and $\mathrm{MCMV}+\mathrm{BLM}+\mathrm{CD} 4^{+} \mathrm{T}$ groups $(\mathrm{P}<0.05)$. No significant difference in body weight was identified among the mice in the BLM, MCMV and MCMV+BLM+CD4 ${ }^{+} \mathrm{T}$ groups ( $\mathrm{P}>0.05$; Fig. 2A). The lung coefficient and HYP content were significantly higher in the BLM, BLM+MCMV and $\mathrm{MCMV}+\mathrm{BLM}+\mathrm{CD} 4^{+} \mathrm{T}$ groups compared with those in the control group $(\mathrm{P}<0.05)$. No such significant difference was identified between the HYP content and lung coefficient between the MCMV and control groups $(\mathrm{P}>0.05)$. Compared with the BLM group, mice in the MCMV+BLM group had an elevated lung coefficient and HYP content $\mathrm{P}<0.05$. Of note, compared with the MCMV+BLM group, mice in the $\mathrm{MCMV}+\mathrm{BLM}+\mathrm{CD} 4^{+} \mathrm{T}$ group had a decreased lung coefficient and HYP content $(\mathrm{P}<0.05$; Fig. $2 \mathrm{~B}$ and $\mathrm{C})$.

BLM exacerbates but $C D 4^{+} T$-cell injection ameliorates pulmonary fibrosis associated with latent respiratory virus infection. HE staining and Masson staining of lung tissues in the control group revealed normal structures of the alveolar wall without inflammatory cell infiltration around the alveoli, and only few blue collagen fibers were present in the alveolar space (Fig. 3A and B). The histology results 
A
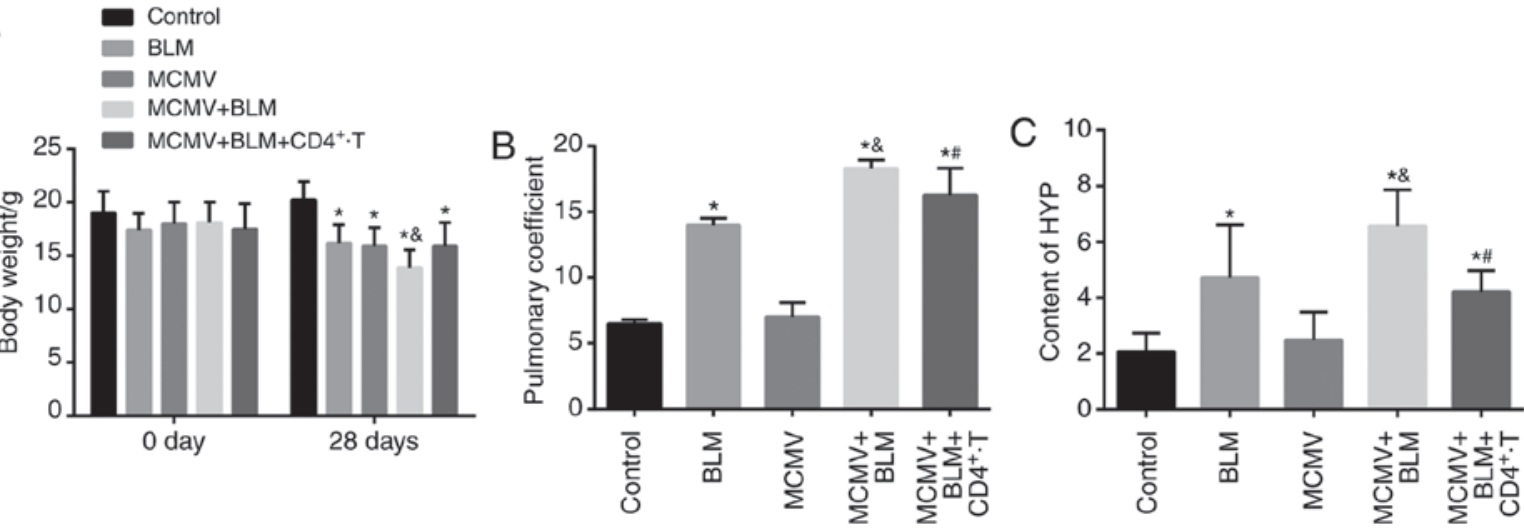

Figure 2. Comparison of (A) the weight, (B) lung coefficient and (C) HYP content in mice among the three groups at days 0 and 28 of the experiment. "P<0.05, compared with the control group; ${ }^{\circledR} \mathrm{P}<0.05$, compared with the BLM group; ${ }^{*} \mathrm{P}<0.05$, compared with the MCMV+BLM group. HYP, hydroxyproline; BLM, bleomycin; T, T-tells; MCMV, murine cytomegalovirus.

A

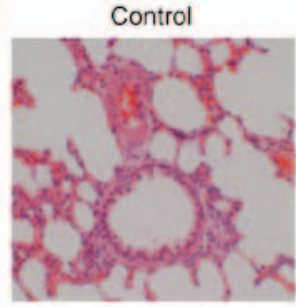

B

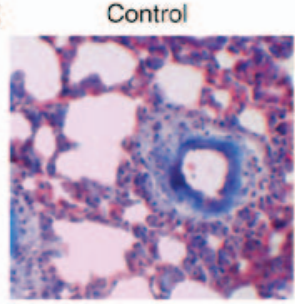

C

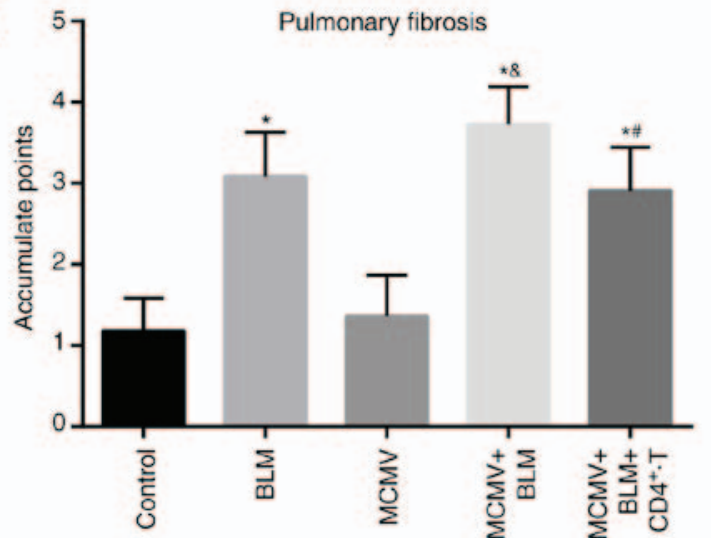

BLM

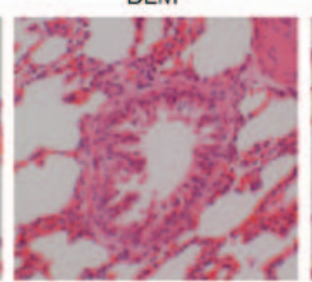

BLM

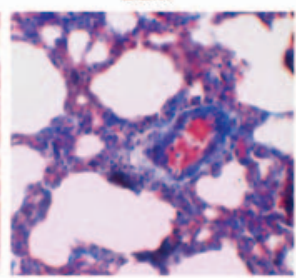

MCMV

MCMV

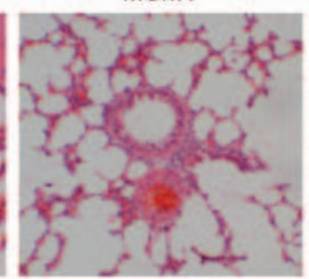

MCMV+BLM

$\mathrm{MCMV}+\mathrm{BLM}+\mathrm{CD} 4^{+} \cdot \mathrm{T}$
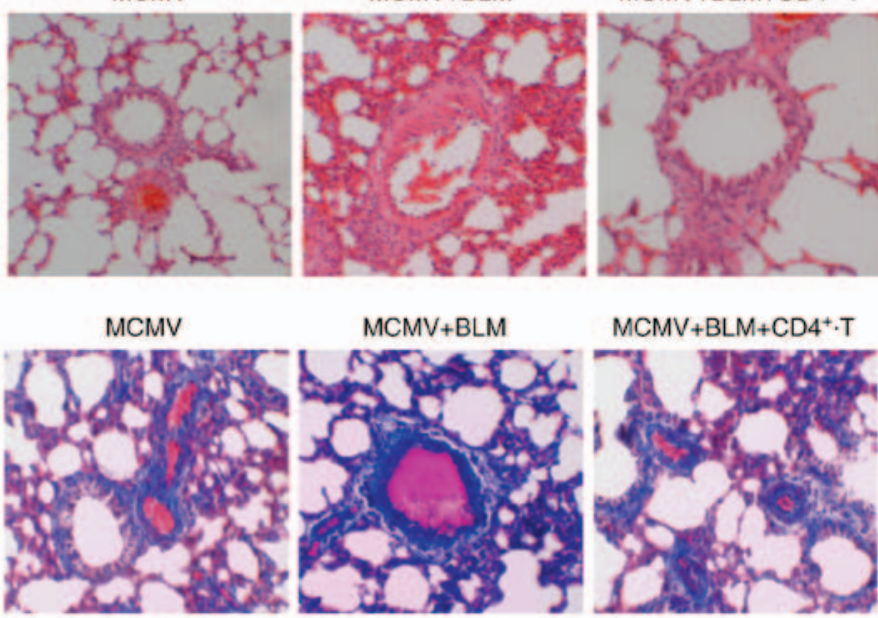

D ${ }^{4} 7 \quad$ Alveolitis

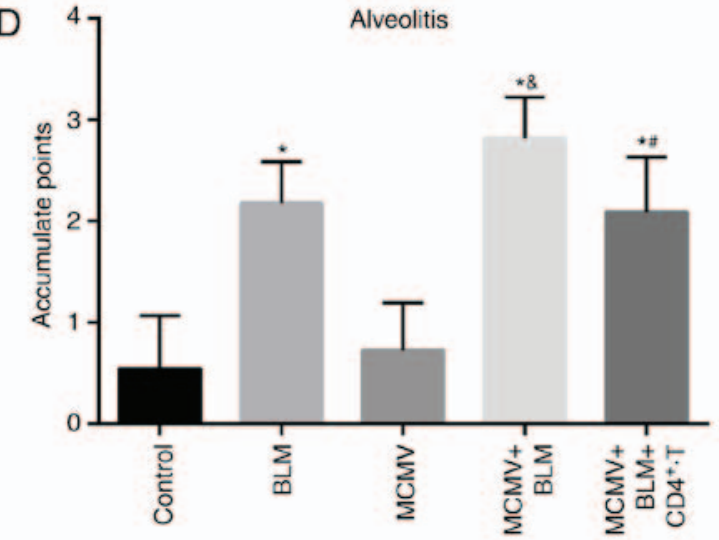

Figure 3. Histopathological changes and scores in each group. (A) HE staining (magnification, x200); (B) Masson staining (magnification, x200); (C) scores of the degree of pulmonary fibrosis; (D) alveolitis scores. ${ }^{*} \mathrm{P}<0.05$, compared with the control group; ${ }^{\circledR} \mathrm{P}<0.05$, compared with the $\mathrm{BLM}$ group; and ${ }^{\#} \mathrm{P}<0.05$, compared with the MCMV+BLM group. BLM, bleomycin; T, T-tells; MCMV, murine cytomegalovirus.

for the MCMV group were similar to those for the control group. In the BLM group, moderate damage to structures of the alveolar wall, infiltration of inflammatory cells in the alveoli and alveolar cavities, hyperemia and edema in the lung interstitium, fibroblast proliferation and an increased number of blue collagen fibers were observed. In the MCMV+BLM group, severe damage to the alveolar structure with massive inflammatory cell infiltration in the alveoli and alveolar cavities, severe hyperemia and edema in the lung interstitium, a high level of fibroblast proliferation and a large amount of blue collagen fibers were observed. Compared with the MCMV+BLM group, the damage in the MCMV+BLM+CD4 ${ }^{+}$ $\mathrm{T}$ group was ameliorated. Quantitative scoring revealed that compared with the control group, mice in the BLM, 


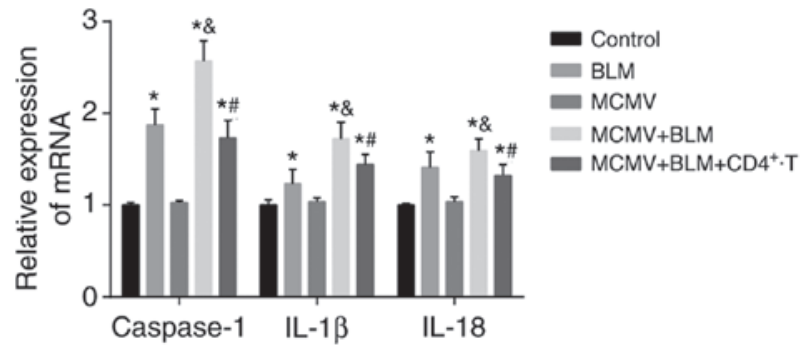

Figure 4. Comparison of the mRNA expression levels of NLRP1 and NLRP3 inflammasome pathway-associated proteins (caspase-1, IL-1 $\beta$ and IL-18) among the three groups. "P $<0.05$, compared with the control group; ${ }^{\&} \mathrm{P}<0.05$, compared with the BLM group; and ${ }^{\#} \mathrm{P}<0.05$, compared with the MCMV+BLM group. BLM, bleomycin; T, T-tells; MCMV, murine cytomegalovirus; IL, interleukin.

MCMV+BLM and MCMV+BLM+CD4 ${ }^{+}$T groups had obviously increased alveolitis and a higher degree of pulmonary fibrosis. In the MCMV+BLM group, these features were also more pronounced than in the BLM group (all $\mathrm{P}<0.05$ ). No significant difference was identified between the MCMV and control groups. Compared with the MCMV+BLM group, the $\mathrm{MCMV}+\mathrm{BLM}+\mathrm{CD} 4^{+} \mathrm{T}$ group exhibited obviously reduced alveolitis and pulmonary fibrosis (Fig. 3C and D).

Latent respiratory virus infection activates NLRPI/NLRP3 inflammasome pathway, evaluated by RT-PCR. Compared with the control group, the BLM, MCMV+BLM and $\mathrm{MCMV}+\mathrm{BLM}+\mathrm{CD} 4^{+} \mathrm{T}$ groups had increased mRNA expression levels of caspase-1, IL-1 $\beta$ and IL-18 in lung tissues (all $\mathrm{P}<0.05$ ), while no significant difference was identified between the MCMV and control groups ( $P>0.05)$. The mRNA expression levels of caspase-1, IL-1 $\beta$ and IL-18 in the lung tissues of the MCMV+BLM group were significantly higher than those in the BLM group (all $\mathrm{P}<0.05$ ). Compared with the MCMV+BLM group, the MCMV+BLM+CD4 ${ }^{+} \mathrm{T}$ group had decreased mRNA expression levels of caspase-1, IL-1 $\beta$ and IL-18 (all P<0.05; Fig. 4).

Latent respiratory virus infection activates NLRPI/NLRP3 inflammasome pathway, evaluated by western blot analysis. No significant difference was identified in the protein expression levels of pro-caspase-1, pro-IL-1 $\beta$ and pro-IL-18 among all groups (all $\mathrm{P}<0.05$ ). The BLM, MCMV+BLM and $\mathrm{MCMV}+\mathrm{BLM}+\mathrm{CD} 4^{+} \mathrm{T}$ groups had increased protein expression levels of caspase-1 (p20), mature IL-1 $\beta$ and mature IL-18 in lung tissues compared with those in the control group (all $\mathrm{P}<0.05$ ). No such significant difference was identified between the MCMV and control groups $(\mathrm{P}>0.05)$. The protein expression levels of caspase-1 (p20), mature IL-1 $\beta$ and mature IL-18 in lung tissues of the MCMV+BLM group were significantly higher than those in the BLM group (all $\mathrm{P}<0.05$ ). Compared with the MCMV+BLM group, the MCMV+BLM+CD4 ${ }^{+} \mathrm{T}$ group had decreased protein expression levels of caspase-1 (p20), mature IL-1 $\beta$ and mature IL-18 (all P<0.05; Fig. 5).

BLM increases but $C D 4^{+} T$-cell injection reduces inflammatory response. Fig. 6 displays the caspase-1, TNF- $\alpha$, IL-1 $\beta$ and IL-18 levels in the serum of mice in each group. Compared with those in the control group, the mice in the $\mathrm{BLM}, \mathrm{MCMV}+\mathrm{BLM}$ and $\mathrm{MCMV}+\mathrm{BLM}+\mathrm{CD} 4^{+} \mathrm{T}$ groups
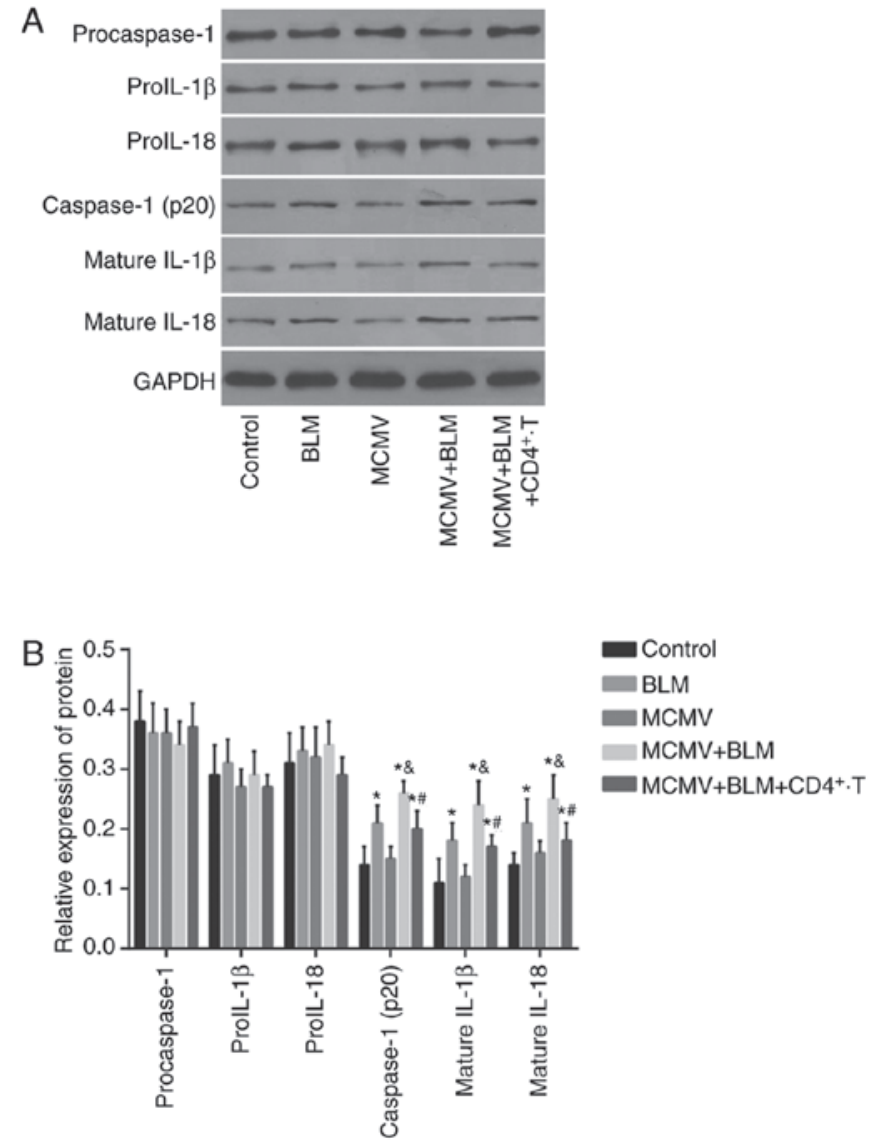

Figure 5. (A and B) Comparison of mRNA expression levels of NLRP1 and NLRP3 inflammasome pathway-associated proteins [(pro)caspase-1, pro/mature IL-1 $\beta$ and pro/mature IL-18) among the three groups. ${ }^{*} \mathrm{P}<0.05$, compared with the control group; ${ }^{\circledR} \mathrm{P}<0.05$, compared with the BLM group; and ${ }^{\#} \mathrm{P}<0.05$, compared with the MCMV+BLM group. BLM, bleomycin; $\mathrm{T}$, T-tells; MCMV, murine cytomegalovirus; IL, interleukin.

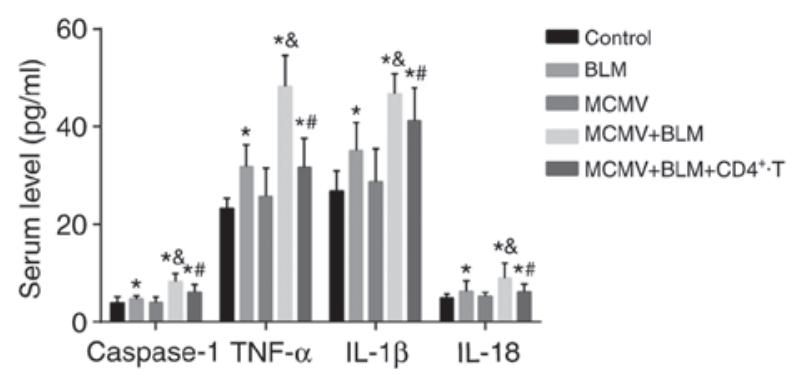

Figure 6. Comparison of the caspase-1, TNF- $\alpha$, IL-1 $\beta$ and IL-18 levels in serum among the three groups. ${ }^{*} \mathrm{P}<0.05$, compared with the control group; ${ }^{\&} \mathrm{P}<0.05$, compared with the BLM group; and ${ }^{\#} \mathrm{P}<0.05$, compared with the MCMV+BLM group. BLM, bleomycin; T, T-tells; MCMV, murine cytomegalovirus; IL, interleukin; TNF, tumor necrosis factor.

had increased serum levels of caspase- 1 , TNF- $\alpha$, IL- $1 \beta$ and IL-18 (all $\mathrm{P}<0.05$ ). No such significant difference was identified between the MCMV and control groups ( $\mathrm{P}>0.05)$. The caspase-1, TNF- $\alpha$, IL-1 $\beta$ and IL-18 levels in the serum of mice in the MCMV+BLM group were significantly higher than those in the BLM group (all $\mathrm{P}<0.05$ ). Compared with the MCMV+BLM group, the MCMV+BLM+CD $4^{+} \mathrm{T}$ group had decreased caspase-1, TNF- $\alpha$, IL-1 $\beta$ and IL-18 levels (all $\mathrm{P}<0.05)$. 


\section{Discussion}

Previous studies have suggested a crucial role of inflammasomes in processing IL- $1 \beta$, affecting the pathogenesis of autoimmune disease, as well as central nervous system infection and injury (22-25). Therefore, the present in vivo study was performed to investigate the role of the NLRP1/NLRP3 inflammasome pathways in MCMV-induced pulmonary fibrosis in mice. The results demonstrated that the NLRP1 and NLRP3 inflammasome pathways are upregulated in MCMV-induced pulmonary fibrosis in mice, which is ameliorated by treatment with $\mathrm{CD} 4^{+} \mathrm{T}$ cells.

The results of the present study indicated that BLM exacerbates but $\mathrm{CD} 4{ }^{+} \mathrm{T}$-cell injection ameliorates pulmonary fibrosis associated with latent respiratory virus infection. Cytomegalovirus (CMV), a major human pathogen, is generally controlled by cellular immune responses (26). CMV, a herpes virus, may contribute to life-threatening pulmonary infections in immunocompromised patients (27). The BLM-induced fibrosis model in mice and rodents has been widely employed by experimental studies for $>20$ years due to its important characteristics of closely mimicking IPF $(28,29)$. Consistent with the present study, Gwinn et al (30) also demonstrated that mice treated with BLM had a reduced weight. HYP is a common index for collagen quantification (31). A previous study verified that BLM-induced fibrosis was associated with an increased lung coefficient and HYP content (32). CD4 ${ }^{+} \mathrm{T}$ (helper) cells have an important role in the immune system, which not only help macrophages respond to intracellular antigens but also help B cells form germinal centers (33). In addition, previous evidence also demonstrated that $\mathrm{T}$ cells inhibited the innate immune response via suppressing NLRP3 and NLRP1 inflammasomes (34). In accordance with this, the MCMV+BLM+CD4 ${ }^{+} \mathrm{T}$ group of the present study had a decreased lung coefficient and HYP content compared with the MCMV+BLM group.

In addition, the present study revealed that NLRP1 and NLRP3 inflammasome pathways were activated when latent respiratory virus infection occurred. Inflammasomes have a crucial role in mediating caspase-1, which promotes the release of IL-1 $\beta$ and IL-18 (35). Previous studies have demonstrated that BLM treatment induced the production of reactive oxygen species, which also activated the NLRP3 inflammasome in numerous cases $(36,37)$. In addition, the production of IL-1 $\beta$ and lung inflammation induced by BLM relies on apoptosis-associated speck-like protein containing a caspase recruitment domain (ASC) (38). Inflammasomes, which are multi-protein complexes, stimulate caspase-1, and inflammasome assembly occurs in response to metabolic reprogramming, which is similar to that triggered by cellular transformation and infection with viruses (including CMV) (39). Furthermore, NLRs only function as sensors of endogenous or exogenous damage-associated molecules, but they also activate caspase- 1 and promote subsequent cleavage of pro-IL-1 $\beta$ and pro-IL-18 cytokines into their mature forms (40). In addition, post-translational cleavage of pro-IL-1 $\beta$ to mature IL-1 $\beta$ is required for its functional activity, which is achieved by the inflammasome via caspase-1 activation (41). Furthermore, activation of T-cells and antigenic stimulation a considered a necessary precondition for blocking NLRP inflammasomes, which agrees with the prior migration of activated $T$ cells to inflammatory sites 42 ).

Furthermore, the present study revealed that BLM increases but $\mathrm{CD}^{+} \mathrm{T}$-cell injection reduces inflammatory response. Cytokines are mainly involved in the pathophysiological and homeostatic regulation of connective tissue, and a complex network consisting of several cytokines has an important role in local injury and the inflammatory response in the lung as well as subsequent tissue repair and fibrosis (43). Previous evidence has demonstrated that TNF- $\alpha$ promoted the development of lung fibrosis (44). The activation and assembly of the inflammasome (consisting of an NLR family member, ASC and pro-caspase-1) was reported to induce the production of caspase-1 (45). Another noteworthy study reported that pharmacologically induced NLRP3 activation may result in interstitial lung disease (46). IL-18, a member of the highly inflammatory cy tokines of the IL-1 family, has a central role in regulating lung inflammation (47). Furthermore, suppression of caspase-1 in lung fibroblasts obviously reduced the expression levels of IL-1 $\beta$ and IL-18 (48). As reflected in one study performed by Huang et al (49), the levels of TNF- $\alpha$, IL- $1 \beta$ and IL-18 were evidently increased in mice after BLM treatment. Previous studies have therefore revealed that BLM stimulates inflammasomes. Finally, the production of active IL-1 $\beta$ activates transforming growth factor- $\beta$, which participates in the development of lung fibrosis $(50,51)$. In addition, CMV infection of immune cells induces the production of a variety of cytokines, including TNF- $\alpha$, IL-1 $\beta$ and IL-6 $(52,53)$. Furthermore, CD41 effector and memory T cells were demonstrated to selectively block the NLRP1 and NLRP3 inflammasomes in an antigen-dependent manner (34). Collectively, NLRP1 and NLRP3 inflammasomes may have increased the inflammatory response in mice with pulmonary fibrosis caused by latent MCMV infection.

In conclusion, employing a mouse model of pulmonary fibrosis, the present study provided evidence that the activation of the NLRP1 and NLRP3 inflammasome pathways may contribute to pulmonary fibrosis caused by latent MCMV infection in mice. Signaling pathways may be affected by various factors and further study should be performed to confirm these conclusions.

\section{Acknowledgements}

Not applicable.

\section{Funding}

No funding was received.

\section{Availability of data and materials}

The datasets used and/or analyzed during the current study are available from the corresponding author on reasonable request.

\section{Authors' contributions}

YHL, XW, SJ, SYG and SMZ contributed to the conception of the work and conduction of the study. SYG and SMZ revised the draft. All authors approved the final version of the manuscript, and agreed for all aspects of the work. 


\section{Ethics approval and consent to participate}

The experimental method was approved by the animal ethics committee of the First Affiliated Hospital of Anhui Medical University (Hefei, China). The animal experiment was performed in strict accordance with the Guidelines for the Care and Use of Laboratory Animals (17).

\section{Consent for publication}

Not applicable.

\section{Competing interests}

The authors declare that they have no competing interests.

\section{References}

1. Huang H, Peng $X$ and Zhong C: Idiopathic pulmonary fibrosis: The current status of its epidemiology, diagnosis, and treatment in China. Intractable Rare Dis Res 2: 88-93, 2013.

2. Loveman E, Copley VR, Scott DA, Colquitt JL, Clegg AJ and O'Reilly KM: Comparing new treatments for idiopathic pulmonary fibrosis-a network meta-analysis. BMC Pulm Med 15: 37, 2015.

3. Lynch JP III, Huynh RH, Fishbein MC, Saggar R, Belperio JA and Weigt SS: Idiopathic Pulmonary fibrosis: Epidemiology, clinical features, prognosis, and management. Semin Respir Crit Care Med 37: 331-357, 2016.

4. King TE Jr, Pardo A and Selman M: Idiopathic pulmonary fibrosis. Lancet 378: 1949-1961, 2011.

5. Strookappe B, Elfferich M, Swigris J, Verschoof A, Veschakelen J, Knevel T and Drent M: Benefits of physical training in patients with idiopathic or end-stage sarcoidosis-related pulmonary fibrosis: A pilot study. Sarcoidosis Vasc Diffuse Lung Dis 32: 43-52, 2015.

6. Dempsey OJ, Kerr KM, Gomersall L, Remmen H and Currie GP: Idiopathic pulmonary fibrosis: An update. QJM 99: 643-654, 2006

7. Spagnolo P, Rossi G and Cavazza A: Pathogenesis of idiopathic pulmonary fibrosis and its clinical implications. Expert Rev Clin Immunol 10: 1005-1017, 2014.

8. Collard HR, Ryerson CJ, Corte TJ, Jenkins G, Kondoh Y, Lederer DJ, Lee JS, Maher TM, Wells AU, Antoniou KM, et al: Acute exacerbation of idiopathic pulmonary fibrosis. An International Working Group Report. Am J Respir Crit Care Med 194: 265-275, 2016.

9. Fernández Pérez ER, Daniels CE, Schroeder DR, St Sauver J, Hartman TE, Bartholmai BJ, Yi ES and Ryu JH: Incidence, prevalence, and clinical course of idiopathic pulmonary fibrosis: A population-based study. Chest 137: 129-137, 2010.

10. Finger JN, Lich JD, Dare LC, Cook MN, Brown KK, Duraiswami C, Bertin J and Gough PJ: Autolytic proteolysis within the function to find domain (FIIND) is required for NLRP1 inflammasome activity. J Biol Chem 287: 25030-25037, 2012.

11. Saresella M, La Rosa F, Piancone F, Zoppis M, Marventano I, Calabrese E, Rainone V, Nemni R, Mancuso R and Clerici M: The NLRP3 and NLRP1 inflammasomes are activated in Alzheimer's disease. Mol Neurodegener 11: 23, 2016.

12. D'Osualdo A and Reed JC: NLRP1, a regulator of innate immunity associated with vitiligo. Pigment Cell Melanoma Res 25: 5-8, 2012.

13. Levandowski CB, Mailloux CM, Ferrara TM, Gowan K, Ben S, Jin Y, McFann KK, Holland PJ, Fain PR, Dinarello CA and Spritz RA: NLRP1 haplotypes associated with vitiligo and autoimmunity increase interleukin-1 $\beta$ processing via the NLRP1 inflammasome. Proc Natl Acad Sci USA 110: 2952-2956, 2013

14. Wang YC, Li WZ, Wu Y, Yin YY, Dong LY, Chen ZW and Wu WN: Acid-sensing ion channel la contributes to the effect of extracellular acidosis on NLRP1 inflammasome activation in cortical neurons. J Neuroinflammation 12: 246, 2015

15. Vandanmagsar B, Youm YH, Ravussin A, Galgani JE, Stadler K, Mynatt RL, Ravussin E, Stephens JM and Dixit VD: The NLRP3 inflammasome instigates obesity-induced inflammation and insulin resistance. Nat Med 17: 179-188, 2011.
16. Rastrick J and Birrell M: The role of the inflammasome in fibrotic respiratory diseases. Minerva Med 105: 9-23, 2014.

17. National Research Council (US) Committee for the Update of the Guide for the Care and Use of Laboratory Animals: Guide for the care and use of laboratory animals: Eighth Edition. Guide for the Care and Use of Laboratory Animals, National Academies Press (US), Washington, 103: pp1072-1073, 2010.

18. Li Y, Gao J, Wang G and Fei G: Latent cytomegalovirus infection exacerbates experimental pulmonary fibrosis by activating TGF- $\beta 1$. Mol Med Rep 14: 1297-1301, 2016.

19. Banczyk D, Kalies K, Nachbar L, Bergmann L, Schmidt P, Bode U, Teegen B, Steven P, Lange T, Textor J, et al: Activated $\mathrm{CD}^{+}{ }^{+} \mathrm{T}$ cells enter the splenic T-cell zone and induce autoantibody-producing germinal centers through bystander activation. Eur J Immunol 44: 93-102, 2014.

20. Szapiel SV, Elson NA, Fulmer JD, Hunninghake GW and Crystal RG: Bleomycin-induced interstitial pulmonary disease in the nude, athymic mouse. Am Rev Respir Dis 120: 893-899, 1979.

21. Livak KJ and Schmittgen TD: Analysis of relative gene expression data using real-time quantitative PCR and the 2(-Delta Delta C(T)) method. Methods 25: 402-408, 2001.

22. Labzin LI, Lauterbach MA and Latz E: Interferons and inflammasomes: Cooperation and counterregulation in disease. J Allergy Clin Immunol 138: 37-46, 2016.

23. Walsh JG, Muruve DA and Power C: Inflammasomes in the CNS. Nat Rev Neurosci 15: 84-97, 2014.

24. Masood H, Che R and. Zhang A: Inflammasomes in the pathophysiology of kidney diseases. Kidney Dis (Basel) 1: 187-193, 2015.

25. Yang $\mathrm{CA}$ and Chiang BL: Inflammasomes and human autoimmunity: A comprehensive review. J Autoimmun 61: 1-8, 2015.

26. Sierro S, Rothkopf R and Klenerman P: Evolution of diverse antiviral $\mathrm{CD}^{+} \mathrm{T}$ cell populations after murine cytomegalovirus infection. Eur J Immunol 35: 1113-1123, 2005.

27. Restrepo-Gualteros SM,Jaramillo-BarberiLE,Gonzalez-Santos M, Rodriguez-Martinez CE, Perez GF, Gutierrez MJ and Nino G: Characterization of cytomegalovirus lung infection in non-HIV infected children. Viruses 6: 2038-2051, 2014.

28. Hoshino T, Nakamura H, Okamoto M, Kato S, Araya S, Nomiyama K, Oizumi K, Young HA, Aizawa H and Yodoi J: Redox-active protein thioredoxin prevents proinflammatory cytokine- or bleomycin-induced lung injury. Am J Respir Crit Care Med 168: 1075-1083, 2003.

29. Boger DL and Cai H: Bleomycin: Synthetic and mechanistic studies. Angewandte Chemie Int Edition 38: 448-476, 2010

30. Gwinn WM, Kapita MC, Wang PM, Cesta MF and Martin WJ II: Synthetic liposomes are protective from bleomycin-induced lung toxicity. Am J Physiol Lung Cell Mol Physiol 301: L207-L217, 2011.

31. Hofman K, Hall B, Cleaver H and Marshall S: High-throughput quantification of hydroxyproline for determination of collagen. Anal Biochem 417: 289-291, 2011.

32. Zhan H, Huang F, Ma W, Zhao Z, Zhang $H$ and Zhang C: Protective effect of ginsenoside Rg1 on bleomycin-induced pulmonary fibrosis in rats: Involvement of caveolin-1 and TGF- $\beta 1$ signal pathway. Biol Pharm Bull 39: 1284-1292, 2016.

33. Banczyk D, Kalies K, Nachbar L, Bergmann L, Schmidt P, Bode U, Teegen B, Steven P, Lange T, Textor J, et al: Activated $\mathrm{CD}^{+} \mathrm{T}$ cells enter the splenic T-cell zone and induce autoantibody-producing germinal centers through bystander activation. Eur J Immunol 44: 93-102, 2014.

34. Guarda G, Dostert C, Staehli F, Cabalzar K, Castillo R, Tardivel A, Schneider P and Tschopp J: T cells dampen innate immune responses through inhibition of NLRP1 and NLRP3 inflammasomes. Nature 460: 269-273, 2009.

35. Viganò E and Mortellaro A: Caspase-11: The driving factor for noncanonical inflammasomes. Eur J Immunol 43: 2240-2245, 2013.

36. Cheresh P, Kim SJ, Tulasiram S and Kamp DW: Oxidative stress and pulmonary fibrosis. Biochim Biophys Acta 1832: 1028-1040, 2013.

37. Saïd-Sadier N and Ojcius DM: Alarmins, inflammasomes and immunity. Biomed J 35: 437-449, 2012.

38. Gasse P, Mary C, Guenon I, Noulin N, Charron S, Schnyder-Candrian S, Schnyder B, Akira S, Quesniaux VF, Lagente V, et al: IL-1R1/MyD88 signaling and the inflammasome are essential in pulmonary inflammation and fibrosis in mice. J Clin Invest 117: 3786-3799, 2007.

39. Guerville F, Daburon S, Marlin R, Lartigue L, Loizon S, Pitard V, Couzi L, Moreau JF, Déchanet-Merville J and Faustin B: TCR-dependent sensitization of human gammadelta $\mathrm{T}$ cells to non-myeloid IL-18 in cytomegalovirus and tumor stress surveillance. Oncoimmunology 4: e1003011, 2015. 
40. Schroder K and Tschopp J: The inflammasomes. Cell 140 821-832, 2010.

41. Mankan AK, Kubarenko A and Hornung V: Immunology in clinic review series; focus on autoinflammatory diseases: Inflammasomes: Mechanisms of activation. Clin Exp Immunol 167: 369-381, 2012.

42. Bromley SK, Mempel TR and Luster AD: Orchestrating the orchestrators: Chemokines in control of $\mathrm{T}$ cell traffic. Nat Immunol 9: 970-980, 2008.

43. Luzina IG, Todd NW, Sundararajan S and Atamas SP: The cytokines of pulmonary fibrosis: Much learned, much more to learn. Cytokine 74: 88-100, 2015.

44. Zhou XM, Wen GY, Zhao Y, Liu YM and Li JX: Inhibitory effects of alkaline extract of Citrus reticulata on pulmonary fibrosis. J Ethnopharmacol 146: 372-378, 2013.

45. Yu HB and Finlay BB: The caspase-1 inflammasome: A pilot of innate immune responses. Cell Host Microbe 4: 198-208, 2008.

46. Kong H, Wang Y, Zeng X, Zhu Q, Xie W and Dai S: Involvement of NLRP3 inflammasome in rituximab-induced interstitial lung disease: A case report. J Clin Pharm Ther 39: 691-694, 2014.

47. De Nardo D, De Nardo CM and Latz E: New insights into mechanisms controlling the NLRP3 inflammasome and its role in lung disease. Am J Pathol 184: 42-54, 2014.
48. Artlett CM, Sassi-Gaha S, Rieger JL, Boesteanu AC, Feghali-Bostwick CA and Katsikis PD: The inflammasome activating caspase 1 mediates fibrosis and myofibroblast differentiation in systemic sclerosis. Arthritis Rheum 63: 3563-3574, 2011.

49. Huang TT, Lai HC, Ko YF, Ojcius DM, Lan YW, Martel J, Young JD and Chong KY: Hirsutella sinensis mycelium attenuates bleomycin-induced pulmonary inflammation and fibrosis in vivo. Sci Rep 5: 15282, 2015.

50. Dostert C, Pétrilli V, Van Bruggen R, Steele C, Mossman BT and Tschopp J: Innate immune activation through Nalp3 inflammasome sensing of asbestos and silica. Science 320: 674-677, 2008.

51. Xu JF, Washko GR, Nakahira K, Hatabu H,Patel AS, Fernandez IE, Nishino M, Okajima Y, Yamashiro T, Ross JC, et al: Statins and pulmonary fibrosis: The potential role of NLRP3 inflammasome activation. Am J Respir Crit Care Med 185: 547-556, 2012.

52. Tong CY, Bakran A, Williams H, Cuevas LE, Peiris JS and Hart CA: Association of tumour necrosis factor alpha and interleukin 6 levels with cytomegalovirus DNA detection and disease after renal transplantation. J Med Virol 64: 29-34, 2001.

53. Contreras A, Botero JE and Slots J: Biology and pathogenesis of cytomegalovirus in periodontal disease. Periodontol 2000 64: 40-56, 2014. 